\title{
Relationship between spectral vegetation indices and crop parameters of maize under nitrogen and water stress
}

\author{
K. RAMACHANDIRAN ${ }^{1 *}$ and S. PAZHANIVELAN ${ }^{2}$ \\ ${ }^{1}$ Department of Agronomy, ${ }^{2}$ Department of Remote Sensing and GIS \\ Tamil Nadu Agricultural University, Coimbatore - 641 003, Tamilnadu, India \\ *Corresponding author E-mail: krchandiran@gmail.com
}

\begin{abstract}
Field experiments were conducted at the Tamil Nadu Agricultural University, Coimbatore, Tamilnadu, India during kharif and rabi season of 2014 with maize crop (TNAU maize hybrid Co 6). To ensure the stressed environment, the crop was subjected to two irrigation levels (IW/CPE: 0.80 and 0.50) and five staggered nitrogen levels $(0,50,75,100$ and 125 per cent of recommended dose of nitrogen (RDN). The experiment was laid out in randomized blocks design RBD (Factorial) with three replications. A higher value of spectral vegetation indices viz., NDVI, GNDVI, RVI, LCI, IR-RED and SR were recorded with irrigation at IW/CPE ratio 0.80 either with 100 or 125 per cent RDN (unstressed) applied to maize crop. Maize under stressed environment recorded reduced values of spectral vegetation indices when the crop was irrigated at 0.50 IW/CPE ratio with no nitrogen. All the spectral vegetation indices expressed positive correlation (highly significant at 1 per cent probability level) with crop parameters. The overall best fit was linear with a regression coefficient between vegetation indices (GNDVI, NDVI) and with crop parameters, and actual grain yield and predicted yield $(0.81$ to 0.85$)$ of maize. The ability of spectral vegetation indices to quantify the combined effect of nitrogen and water stress on maize too early through remote sensing paves the way for large scale application of satellite remote sensing.
\end{abstract}

Key words: Nitrogen, water, stress, spectral vegetation indices, maize.

Stress come from a range of factors that limit the potential growth of canopies. Evaluation of the stress level to which plants are subjected to is, therefore, vital both for the quantification of consequences on production and for taking action for their mitigation. Remote sensing is a good tool to detect and quantify the impact of plant stress compared to visual techniques because a vegetative unit can be repeated, objectively, and non-destructively examined in a fast, robust, accurate, and inexpensive manner (Mirik et al., 2012). The launch of new hyperspectral remote sensing satellites, the focus of current research has been shifted to investigate the possibilities of hyperspectral remote sensing in crop monitoring. Hyperspectral remote sensing techniques allow the early detection of vegetation stress, before the appearance of visible symptoms (Panigada et al., 2010).

Using absorption and spectral reflection characteristics of vegetation researchers have defined many vegetation indices for monitoring vegetation parameters. Spectral vegetation indices were designed to evaluate vegetation condition, foliage, cover, phenology, and processes, in addition, to be used for land cover classification, climate and land use detection, drought monitoring, and habitat loss (Padilla et al., 2011).

The advent of spectral mapping and identification of vegetation by remote sensing methods, assumes importance to study crop stress using remote sensing techniques in maize under stressed conditions. Keeping this in view an experiment was planned for earlier determination of nitrogen and water stress with hyperspectral reflectance and vegetation indices on maize with the objectives, to quantify the relationship between vegetation indices and crop parameters of maize and to study the effect of nitrogen and water stress on maize using spectral vegetation indices.

\section{MATERIALS AND METHODS}

\section{Study area}

A field experiment was conducted at Tamil Nadu Agricultural University, Coimbatore, Tamilnadu, India during kharif and rabi 2014 with maize crop (TNAU maize hybrid Co 6). The site of the experiment is located at N $11^{\circ} 0$ ' $33.4^{\prime \prime}$ E76 $56^{\prime} 25.7^{\prime \prime}$ and 430.5 MSL in a subtropical belt. The soil is sandy clay loam in texture and the soil is alkaline in reaction with a $\mathrm{pH}$ of 8.41 . The soil was medium in organic carbon $(0.62 \%)$, Low available nitrogen $\left(186 \mathrm{~kg} \mathrm{ha}^{-1}\right)$, 
Table 1: Spectral indices and ratio of spectral wavebands used to differentiate nitrogen and water stress in maize

\begin{tabular}{lcll}
\hline Index & Abbreviation & \multicolumn{1}{c}{ Formula } & Reference \\
\hline Normalized difference vegetation index & NDVI & $\left(\mathrm{R}_{850}-\mathrm{R}_{670} /\left(\mathrm{R}_{850}+\mathrm{R}_{670}\right)\right.$ & Rouse et al., (1973) \\
Green NDVI & GNDVI & $\left(\mathrm{R}_{780}-\mathrm{R}_{550} /\left(\mathrm{R}_{780}+\mathrm{R}_{550}\right)\right.$ & Aparicio et al., (2000) \\
Ratio vegetation index & $\mathrm{RVI}$ & $\left(\mathrm{R}_{927} / \mathrm{R}_{687}\right)$ & Thenkabail et al., (2000) \\
Leaf chlorophyll index & $\mathrm{LCI}$ & $\left(\mathrm{R}_{850}-\mathrm{R}_{710}\right) /\left(\mathrm{R}_{850}+\mathrm{R}_{680}\right)$ & \\
Infrared-red index & IR-RED & $\left(\mathrm{R}_{789} / \mathrm{R}_{663}\right)$ & Genc et al., (2011) \\
Simple ratio & $\mathrm{SR}$ & $\left(\mathrm{R}_{900} / \mathrm{R}_{680}\right)$ & Gitelson and Merzlyak, (1996) \\
\hline
\end{tabular}

medium available phosphorus $\left(13 \mathrm{~kg} \mathrm{ha}^{-1}\right)$ and high available potassium $\left(367 \mathrm{~kg} \mathrm{ha}^{-1}\right)$. The soil moisture retention is 24.3 $\%$ at 0.33 bars and $10.2 \%$ at 15 bars.

\section{Experimental design}

To ensure the stressed environments, the crop was subjected to two irrigation levels and five staggered nitrogen levels. The experiment was laid out in RBD (Factorial) with three replications and the details of the treatments are as follows. The irrigation regimes were $\mathrm{W}_{1}$ (IW/CPE: 0.80) and $\mathrm{W}_{2}(\mathrm{IW} / \mathrm{CPE}: 0.50)(\mathrm{IW}=5 \mathrm{~cm})$ and the nitrogen levels were $\mathrm{N}_{0}$ : No nitrogen, $\mathrm{N}_{1}: 50 \% \mathrm{RDN}, \mathrm{N}_{2}: 75 \% \mathrm{RDN}, \mathrm{N}_{3}: 100 \%$ RDN and $\mathrm{N}_{4}: 125 \%$ RDN (RDN: Recommended dose of nitrogen). The generally recommended dose of fertilizers for hybrid maize is 250:75:75 $\mathrm{NPK} \mathrm{kg} \mathrm{ha}^{-1}$ as per the package of practice suggested by the Department of Agriculture, Government of Tamilnadu and Tamil Nadu Agricultural University, Coimbatore.

\section{Spectral reflectance measurements}

Hyperspectral data were collected from plant canopy by using GER 1500 portable spectroradiometer which has 512 channels ranging from $350-1050 \mathrm{~nm}$ with $1.5-3.2 \mathrm{~nm}$ bandwidths. The reflectance measurements were made on sunny days. Calibration of the radiometer was done with the help of barium sulfate coated plate in the field before and after taking canopy reflectance measurement. The canopy reflectance was computed as the ratio of canopy radiances to the radiance from the white reference plate. The spectral characteristics of the crop were measured at 60 and 90 days after sowing.

\section{Spectral vegetation indices}

Spectral reflectance indices viz., NDVI, GNDVI, RVI, LCI, IR-RED and SR (Table 1) were calculated, where R and subscript number indicate the reflectance at the specific wavelength. The reflectance data were transformed into vegetation indices and used to distinguish nitrogen and water stress severity in maize. The correlation studies were done by using SPSS (16.0).

\section{RESULTS AND DISCUSSION}

\section{Spectral signature}

Measured spectral reflectance curve of maize exhibited a broad low intensity peak centered in the green region at $550 \mathrm{~nm}$ and a sharp rise starting at about $675 \mathrm{~nm}$ to a plateau in the vicinity of $762 \mathrm{~nm}$. Spectral reflectance of maize varied from different irrigation regimes and changed with nitrogen levels. Irrigation at IW/CPE ratio 0.80 with $100 \%$ RDN (unstressed) of maize showed that low reflectance in visible region (400 to $700 \mathrm{~nm}$ ) and high in near infra red (NIR) region (700 to 900). Under stressed condition the reflectance was high in visible region and low in NIR region at IW/CPE ratio 0.50 with no nitrogen compare to unstressed maize at 60 DAS (Fig. 1). Similar reflectance pattern of maize crop was observed at 90 DAS.

Spectral signature from different nitrogen levels within the irrigation regimes also varied. While similar reflectance pattern of maize was observed under nitrogen levels, the percent of reflectance was high in visible region and low in NIR region with no nitrogen as compare to all other nitrogen levels within irrigation regimes (Fig. 2 and 3). Whereas the spectral signature slightly decreased in visible spectrum and increased in NIR region when nitrogen dose was increased to 50, 75 and $100 \%$ RDN of maize crop. As in line with the trend, spectral reflectance of maize crop at $125 \%$ RDN was found that to be very low in visible region and very high in NIR region. Similar reflectance pattern of maize crop was observed at 60 and 90 DAS.

Among different irrigation regimes of 0.50 and 0.80 IW/CPE radio, water stressed maize crop (IW/CPE: 0.50) had higher reflectance than unstressed maize (IW/CPE: 0.80 ) in the visible spectrum in contrast to much higher reflectance from unstressed plants when compared to lower 

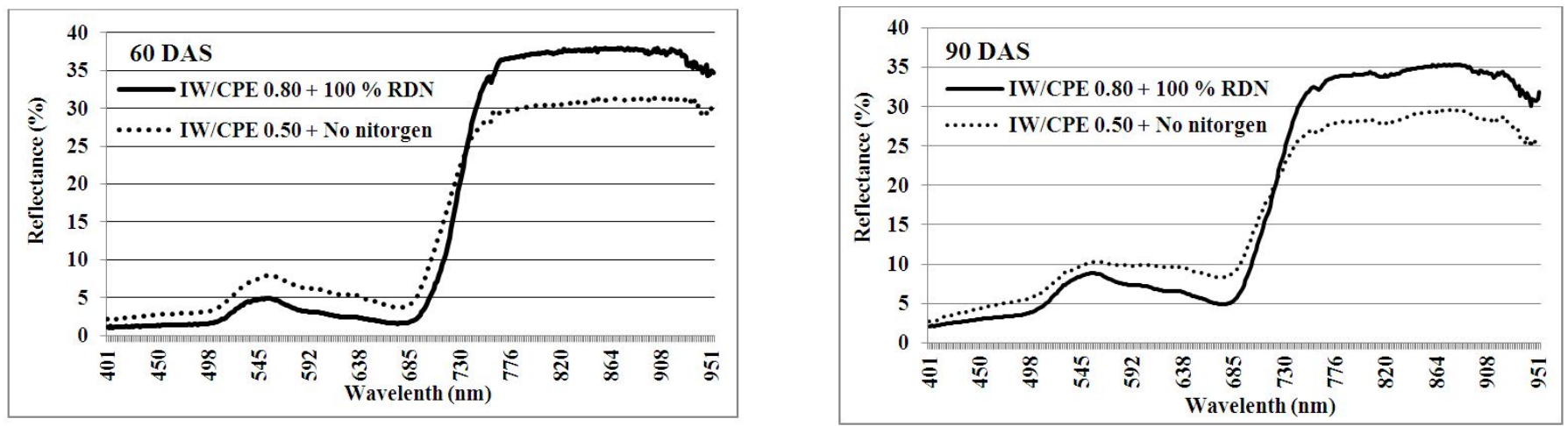

Fig. 1: Spectral signature characters of unstressed (IW/CPE ration: $0.80+100 \% \mathrm{RDN}$ ) and stressed (IW/CPE ratio: $0.50+$ No nitrogen) maize crop at 60 and 90 DAS.
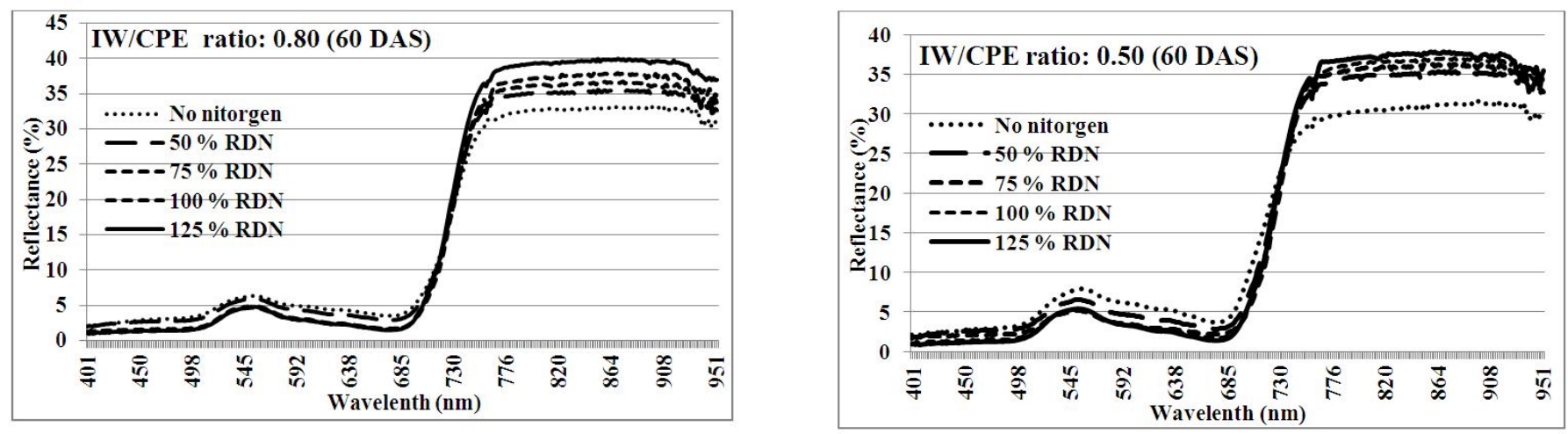

Fig. 2: Spectral signature characters of maize crop with irrigation at IW/CPE ration: 0.80, 0.50 and different nitrogen levels viz., No nitrogen, $50 \%$ RDN, $75 \%$ RDN, $100 \%$ RDN and $125 \%$ RDN at 60 DAS.
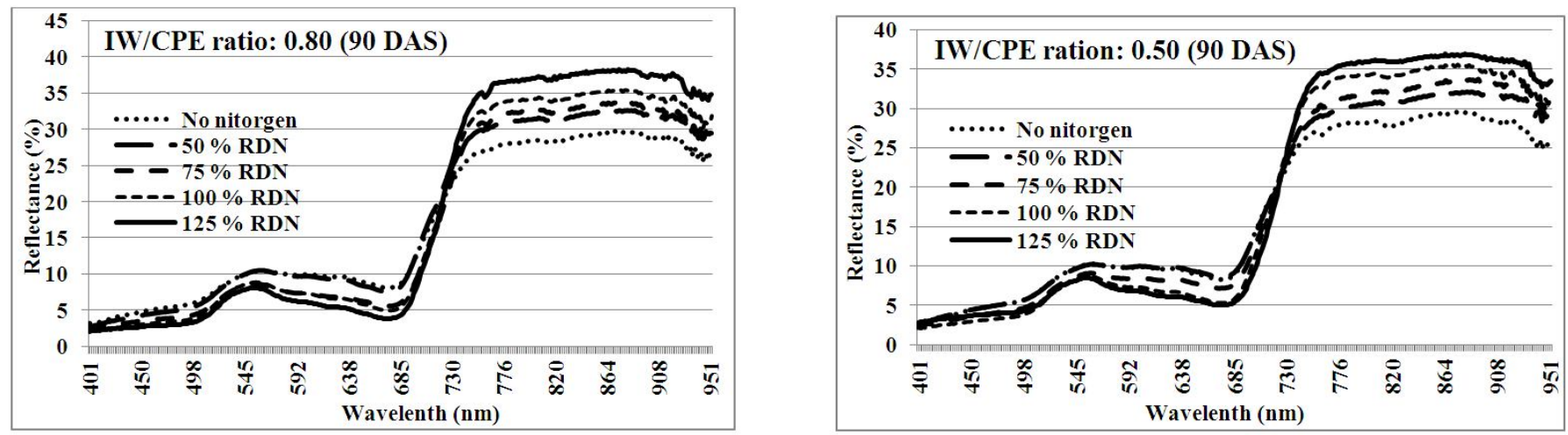

Fig. 3: Spectral signature characters of maize crop with irrigation at IW/CPE ration: $0.80,0.50$ and different nitrogen levels viz., No nitrogen, $50 \%$ RDN, $75 \%$ RDN, $100 \%$ RDN and $125 \%$ RDN at 90 DAS.

reflectance from stressed plants in the NIR spectrum at 60 and 90 DAS (Fig. 2 and 3).

\section{Spectral vegetation indices}

A higher value of spectral vegetation indices viz., NDVI, GNDVI, RVI, LCI, IR-RED and SR were recorded with irrigation at IW/CPE ratio 0.80 either with 100 or 125 per cent RDN (unstressed) applied to maize crop. Maize under stressed environment recorded low values of spectral vegetation indices values when the crop was irrigated at $0.50 \mathrm{IW} / \mathrm{CPE}$ ratio with no nitrogen (stressed). The value of vegetation indices increased with increased nitrogen levels of 50,75, 100, 125 percent of RDN. However the lowest values of spectral vegetation indices were recorded under nitrogen stressed condition compard to all other nitrogen levels. Among the irrigation regimes, irrigation at $0.80 \mathrm{IW} /$ 
Table 2: Effect of irrigation and nitrogen levels on spectral vegetation indices of maize (Pooled data)

\begin{tabular}{|c|c|c|c|c|c|c|c|c|c|c|c|c|}
\hline \multirow[t]{2}{*}{ Treatments } & \multicolumn{2}{|c|}{ NDVI } & \multicolumn{2}{|c|}{ GNDVI } & \multicolumn{2}{|c|}{ RVI } & \multicolumn{2}{|c|}{ LCI } & \multicolumn{2}{|c|}{ IR-RED } & \multicolumn{2}{|c|}{ SR } \\
\hline & $\mathrm{W}_{1}$ & $\mathrm{~W}_{2}$ & $\mathrm{~W}_{1}$ & $\mathrm{~W}_{2}$ & $\mathrm{~W}_{1}$ & $\mathrm{~W}_{2}$ & $\mathrm{~W}_{1}$ & $\mathrm{~W}_{2}$ & $\mathrm{~W}_{1}$ & $\mathrm{~W}_{2}$ & $\mathrm{~W}_{1}$ & $\mathrm{~W}_{2}$ \\
\hline \multicolumn{13}{|c|}{60 DAS } \\
\hline $\mathbf{N}_{0}$ & 0.7888 & 0.7408 & 0.6584 & 0.6094 & 7.65 & 6.07 & 0.6745 & 0.6192 & 28.08 & 25.47 & 8.36 & 6.46 \\
\hline $\mathbf{N}_{1}$ & 0.8288 & 0.7973 & 0.7047 & 0.6725 & 9.53 & 7.88 & 0.7128 & 0.6810 & 30.08 & 28.80 & 10.40 & 8.51 \\
\hline $\mathbf{N}_{2}$ & 0.8610 & 0.8396 & 0.7317 & 0.7186 & 11.98 & 10.42 & 0.7476 & 0.7276 & 31.59 & 30.49 & 13.28 & 11.30 \\
\hline $\mathbf{N}_{3}$ & 0.8993 & 0.8682 & 0.7876 & 0.7703 & 16.95 & 13.19 & 0.7972 & 0.7785 & 35.66 & 34.18 & 18.83 & 14.38 \\
\hline $\mathbf{N}_{4}$ & 0.9286 & 0.9039 & 0.8415 & 0.8181 & 23.55 & 17.67 & 0.8428 & 0.8139 & 39.01 & 37.59 & 26.38 & 19.39 \\
\hline \multicolumn{13}{|c|}{90 DAS } \\
\hline $\mathbf{N}_{0}$ & 0.5714 & 0.5567 & 0.4730 & 0.4630 & 3.40 & 3.17 & 0.3859 & 0.3684 & 20.08 & 19.55 & 3.67 & 3.47 \\
\hline $\mathbf{N}_{1}$ & 0.6272 & 0.5833 & 0.5127 & 0.5051 & 4.00 & 3.60 & 0.4214 & 0.4178 & 23.42 & 21.78 & 4.38 & 3.84 \\
\hline $\mathbf{N}_{2}$ & 0.7080 & 0.6500 & 0.5814 & 0.5570 & 5.35 & 4.47 & 0.5376 & 0.4772 & 26.43 & 24.31 & 5.82 & 4.78 \\
\hline $\mathbf{N}_{3}$ & 0.7475 & 0.7238 & 0.6066 & 0.5982 & 6.37 & 5.72 & 0.5611 & 0.5463 & 28.82 & 28.26 & 7.01 & 6.23 \\
\hline $\mathbf{N}_{4}$ & 0.8116 & 0.7577 & 0.6628 & 0.6343 & 9.04 & 6.86 & 0.6339 & 0.6072 & 32.67 & 30.45 & 9.92 & 7.40 \\
\hline
\end{tabular}

$\mathrm{W}_{1}(\mathrm{IW} / \mathrm{CPE}: 0.80)$ and $\mathrm{W}_{2}(\mathrm{IW} / \mathrm{CPE}: 0.50)$ and $\mathrm{N}_{0}$ : No nitrogen, $\mathrm{N}_{1}: 50, \mathrm{~N}_{2}: 75, \mathrm{~N}_{3}: 100$ and $\mathrm{N}_{4}: 125 \% \mathrm{RDN}$

Table 3: Pearson correlation coefficients between spectral vegetation indices and crop parameters of maize under irrigation and nitrogen levels (as per pooled data)

\begin{tabular}{|c|c|c|c|c|c|c|c|c|}
\hline & \multicolumn{4}{|c|}{$60 \mathrm{DAS}$} & \multicolumn{4}{|c|}{$90 \mathrm{DAS}$} \\
\hline & LAI & $\begin{array}{c}\text { Total } \\
\text { chlorophyll }\end{array}$ & Proline & Yield & LAI & $\begin{array}{c}\text { Total } \\
\text { chlorophyll }\end{array}$ & Proline & Yield \\
\hline NDVI & $.950^{* *}$ & $.963^{* *}$ & $-.774^{* *}$ & $.923^{* *}$ & $.941^{* *}$ & $.939^{* *}$ & $-.737^{*}$ & $.902^{* *}$ \\
\hline GNDVI & $.919^{* *}$ & $.933^{* *}$ & $-.710^{*}$ & $.877^{* *}$ & $.913^{* *}$ & $.909^{* *}$ & $-.665^{*}$ & $.870^{* *}$ \\
\hline RVI & $.906^{* *}$ & $.915^{* *}$ & $-.723^{*}$ & $.847^{* *}$ & $.898^{* *}$ & $.902^{* *}$ & $-.695^{*}$ & $.837^{* *}$ \\
\hline LCI & $.928^{* *}$ & $.943^{* *}$ & $-.736^{*}$ & $.895^{* *}$ & $.904^{* *}$ & $.900^{* *}$ & $-.665^{*}$ & $.857^{* *}$ \\
\hline IR-RED & $.903^{* *}$ & $.917^{* *}$ & $-.695^{*}$ & $.854^{* *}$ & $.929^{* *}$ & $.926^{* *}$ & $-.693^{*}$ & $.882^{* *}$ \\
\hline SR & $.908^{* *}$ & $.916^{* *}$ & $-.730^{*}$ & $.850^{* *}$ & $.900^{* *}$ & $.905^{* *}$ & $-.704^{*}$ & $.841^{* *}$ \\
\hline
\end{tabular}

*. Correlation is significant at the 0.05 level **. Correlation is significant at the 0.01 level

$\mathrm{CPE}$ ratio recorded higher values of the spectral vegetation indices. Irrigation at $0.5 \mathrm{IW} / \mathrm{CPE}$ and subsequent water stress resulted into reduction in values of these spectral indices at 60 and 90 DAS (Table 2).

It is quite clear that the vegetation indices value for the stressed plants is much less than the healthy plants due to decreased reflectance in NIR region and increased reflectance in the visible region.

\section{Relationship between spectral vegetation indices and crop parameters}

The Pearson correlation coefficients between spectral vegetation indices and crop parameters viz., leaf area index, total chlorophyll content, proline content and grain yield at different plant growth stages of 60 and 90 DAS were significantly influenced by nitrogen levels and irrigation regimes as per pooled data over the two seasons (Table 3).

The relationship between vegetation indices viz., NDVI, GNDVI, RVI, LCI, IR-RED and SR had better correlation with crop growth parameters. Especially all the spectral vegetation indices expressed high or positive correlation with significance at the 0.01 level with LAI, total chlorophyll content and yield with a correlation coefficient of $>0.80$ and Proline $>-0.70$ both at 60 and 90 DAS for the pooled data over the two seasons. All these spectral vegetation indices had high positive inter-correlation with values of $>0.90$. 

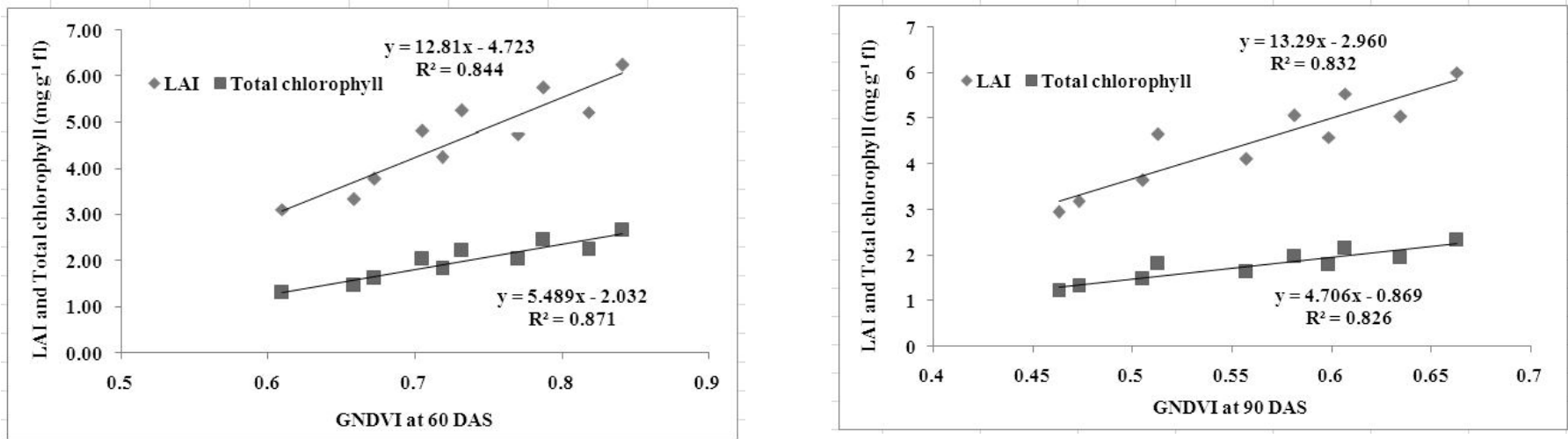

Fig. 4: Relationship between GNDVI $V_{S}$ LAI and total chlorophyll content (as per pooled data)
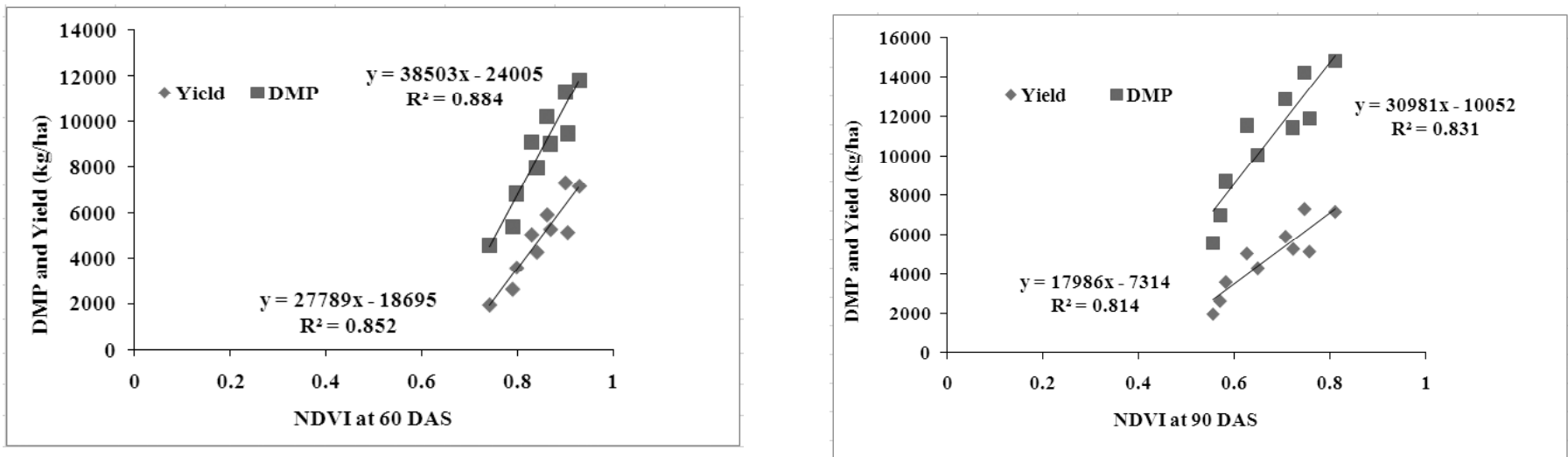

Fig. 5: Relationship between NDVI $V_{S}$ DMP and yield of maize (as per pooled data)
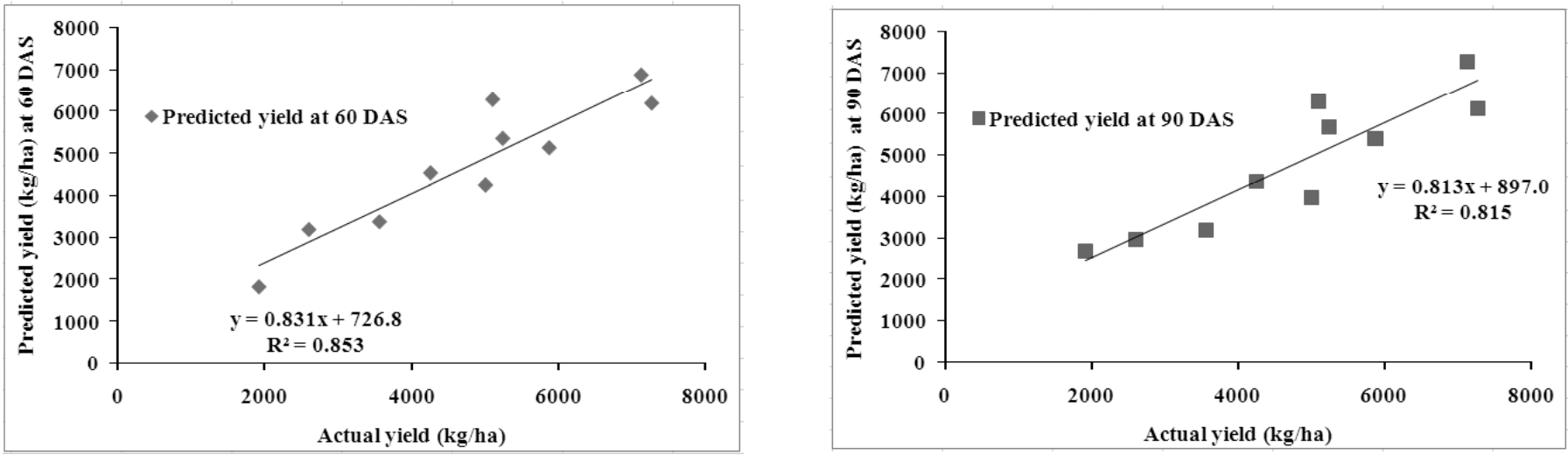

Fig. 6: Relationship between actual yield and predicted yield of maize (as per pooled data)

The relationship between NDVI and LAI for pooled data over the two years, the overall best fit was exponential with a coefficient of determination (0.85) as reported by Jayasree et al. (2013). An exponential relationship between LAI and NDVI was observed for soybean, beans, peas, corn and wheat by Haboudane et al. (2004). The study by Pradhan et al. (2013) revealed the significance of GNDVI correlating yield and stress in wheat.

\section{Regression coefficient}

The regression coefficients between spectral vegetation indices (NDVI, GNDVI) and crop parameters viz., leaf area index, total chlorophyll content, DMP and grain yield at different plant growth stages of 60 and 90 DAS were significantly influenced by nitrogen levels and irrigation regimes as per pooled data over the two seasons.

Prediction equations were developed between the GNDVI with measured LAI and measured total chlorophyll content. The overall best fit was linear with a regression coefficient of determination of $\mathrm{R}^{2}$ value from 0.83 to 0.84 and 0.82 to 0.87 per cent, respectively (Fig. 4). 
Prediction equations were developed between the NDVI with measured dry matter production (DMP) and measured grain yield. The overall best fit was linear with coefficient of determination $\left(\mathrm{R}^{2}\right)$ values from 0.83 to 0.88 and 0.81 to 0.85 per cent respectively (Fig. 5).

Prediction equations were developed between the predicted maize grain yield (based on NDVI derived data) and observed grain yield. It indicated that there was a good agreement between the predicted and observed grain yield (Fig. 6). The results clearly indicated that the grain yield could be estimated and quantified at the large scale through NDVI derived from the satellite driven remote sensing data over a large area. Similar observation was made by Wiegand and Richardson (1990) with respect to spectral vegetation indices.

\section{CONCLUSION}

Remote sensing techniques to assess the combined effect of nitrogen and water stress in maize using hyperspectral reflectance spectra transformed into spectral vegetation indices. The spectral indices viz., NDVI, GNDVI, RVI, LCI, IR-RED and SR recorded higher value on unstressed maize crop and plants under stress caused a reduction in value of these indices at 60 and 90 DAS in both the seasons. All the spectral vegetation indices expressed significant positive correlation with crop parameters.

\section{ACKNOWLEDGEMENT}

This work has been undertaken with financial support from UGC, New Delhi under major research projects scheme.

\section{REFERENCES}

Aaricio, N., Villegas, D., Casadensus, J., Araus, L. and Royo, C. (2000). Spectral vegetation indices as nondestructive tools for determining durum wheat yield. Agron. J., 92: 83-91.

Genc, L., Demirel, K., Camoglu, G., Asik, S. and Smith, S. (2011). Determination of plant water stress using spectral reflectance measurements in watermelon (Citrullus vulgaris). American-Eura. J. Agric. Environ. Sci., 11(2): 296-304.
Gitelson, A.A. and Merzlyak, N. (1996). Signature analysis of leaf reflectance spectra: algorithm development for remote sensing of chlorophyll. J. Plant Physiol., 148: 494-500.

Haboudane, D., Miller, J.R., Tremblay, N. and Pattey, E. (2004). Estimation of LAI using ground spectral measurements over agricultural crops: Predication capability assessment of optical indices. Canadian J. Remote Sen., 23: 143162.

Jayasree, G., Lingalah, D., Reddy, D.R. and Narasimha Rao, S.B.S. (2013). Relationship between biophysical parameters and normalized difference vegetation index in maize. J. Agrometeorol., 15(2): 120-125.

Mirik, M., Ansley, R.J., Michels, J.G.J. and Elliott, N.C. (2012). Spectral vegetation indices selected for quantifying Russian wheat aphid (Diuraphis noxia) feeding damage in wheat (Triticum aestivum L.). Precision Agric., 13: 501-516.

Padilla, F.L.M., Gonzalez-Dugo, M.P., Gavilan, P. and Dominguez, J. (2011). Integration of vegetation indices into a water balance model to estimate evapotranspiration of wheat and corn. Hydrol. Earth Sys. Sci., 15: 1213 1225 .

Panigada, C., Busetto, L., Meroni, M., Amaducci, S., Rossini, M., Cogliati, S., Boschetti, M.,Picchi, V., Marchesi, A., Pinto, F., Rascher,U. andColombo, R. (2010). EDOCROS: Early detection of crop water and nutritional stress by remotelysensed indicators. In: $4^{\text {th }}$ International workshop on remote sensing of vegetation fluorescence, 15-17 NOV. 2010, Valencia (SPAIN).

Pradhan, S., Chopra, U.K., Bandyopadhyay, K.K., Krishnan, P., Singh, R. and Jain,A.K. (2013). Soil waterdynamics, root growth and water and nitrogen use efficiency of rainfed maize (Zea mays) in a semi-arid environment. Indian J. Agric. Sci., 83(5): 542-548.

Wiegand, C.L. and Richardson, A.J. (1990). Use of spectral vegetation indices to infer the leaf area, evapotranspiration and yield:1 Rational. Agron. J., 82: 623-629. 